\title{
Unsuccessful treatment of non-gonococcal urethritis with rosoxacin provides information on the aetiology of the disease
}

\author{
D A HAWKINS, ${ }^{*}+$ D TAYLOR-ROBINSON, ${ }^{*}+\mathrm{R}$ T EVANS, ${ }^{*} P$ M FURR, ${ }^{*}$ AND \\ J R W HARRISt \\ From the *Division of Sexually Transmitted Diseases, MRC Clinical Research Centre, Harrow, Middlesex \\ and the †Praed Street Clinic, St Mary's Hospital, London
}

SUMMARY In a controlled trial of rosoxacin in patients with non-gonococcal urethritis (NGU), $150 \mathrm{mg}$ of the antibiotic given twice daily for 10 days was compared with $300 \mathrm{mg}$ triple tetracycline (Deteclo) given twice daily for the same period. Only six (19\%) of 31 patients treated with rosoxacin were free of urethritis after 10 days; Chlamydia trachomatis was reisolated from 12 $(92 \%)$ of 13 patients who were chlamydia positive originally, and Ureaplasma urealyticum was reisolated from $12(80 \%)$ of 15 patients who were ureaplasma positive originally. In contrast, 18 $(58 \%)$ of 31 patients treated with triple tetracycline were cured clinically after 10 days; $C$ trachomatis was not reisolated from any of 10 patients who were chlamydia positive originally, and $U$ urealyticum was reisolated from only three $(17 \%)$ of 18 patients who were ureaplasma positive originally. These results were consistent with the antimicrobial inactivity of rosoxacin in vitro and they cannot be reconciled with previous reports of successful use of this antibiotic in NGU. Ureaplasmas were isolated more frequently and in larger numbers from chlamydia negative than from chlamydia positive patients, but it is probable that ureaplasmas resistant to tetracycline were not responsible for persistent urethritis.

\section{Introduction}

Rosoxacin is a pyridyl quinolone antibacterial agent related to nalidixic acid, which is rapidly absorbed by mouth and is active against Gram negative bacteria. It is used to treat acute gonorrhoea, and is effective against penicillin sensitive and insensitive (including $\beta$-lactamase producing) strains of Neisseria gonorrhoeae. A single dose of $300 \mathrm{mg}$ clears most uncomplicated urethral gonococcal infections, but has not eradicated Chlamydia trachomatis or shown an effect on the development of postgonococcal urethritis. ${ }^{12}$ This is perhaps not surprising because active drugs are often not effective clinically when given in a single dose. A group of French workers has reported repeatedly that rosoxacin given over a more prolonged period is effective in curing genital infections caused by $C$ trachomatis. ${ }^{34}$ They claimed

Address for reprints: Dr D A Hawkins, Division of Sexually Transmitted Diseases, MRC Clinical Research Centre, Watford Road, Harrow, Middlesex HA1 3UJ

Accepted for publication 17 April 1984 that $150 \mathrm{mg}$ given twice daily for 10 days eradicated chlamydiae and produced a satisfactory clinical response with few side effects in patients with nongonococcal urethritis (NGU). The results of our preliminary in vitro tests with rosoxacin were not promising. As clinical responses do not always correlate well with the results of laboratory tests, however, and in view of the results of others, we undertook a clinical trial of rosoxacin compared with triple tetracycline in patients with NGU.

\section{Patients and methods}

PATIENTS AND STUDY DESIGN

The clinical study, for which ethical committee approval had been obtained, was undertaken at the Praed Street Clinic. Men were included if they (a) were symptomatic, (b) had a Gram stained urethral smear that contained $\geqslant 15$ polymorphonuclear leucocytes (PMNL) per high power microscope field ( $\times 1000)$ and cultures for $N$ gonorrhoeae were negative, (c) did not have complicating factors such as genital herpesvirus infection, intrameatal warts, or 
Trichomonas vaginalis, (d) had not taken antibacterial drugs for at least two months, (e) were unlikely to have glucose 6-phosphate dehydrogenase deficiency, and (f) had given informed consent to participate in the study.

Eighty four men with NGU were recruited and allocated randomly to single blind treatment with either rosoxacin $150 \mathrm{mg}$ twice daily for 10 days or a triple tetracycline (Deteclo) $300 \mathrm{mg}$ twice daily for the same period. Appropriate instructions to avoid milk products were given by the pharmacy to the group of patients receiving triple tetracycline, and all patients were asked to refrain from sexual intercourse during the trial. All patients were assessed clinically and microbiologically by the same doctor initially and 10 and 17 days later. At follow up visits specific questions were asked about symptoms, side effects, and the possibility of reinfection. Patients not responding satisfactorily by day 10 (and who had $\geqslant 5 \mathrm{PMNL} /$ high power field) were treated with triple tetracycline $300 \mathrm{mg}$ twice daily for seven days. If further treatment was necessary it was given on an empirical basis.

\section{EVALUATION OF TREATMENT}

Recovery was considered to be complete if symptoms were absent and there were $\leqslant 4 \mathrm{PMNL} /$ high power field and to be partial if symptoms had improved but there were still 5-15 PMNL/high power field. Treatment was considered to have failed if there was no improvement in symptoms or signs.

SPECIMENS AND LABORATORY

INVESTIGATIONS

Urethral specimens for Gram staining and subsequent culture for $N$ gonorrhoeae were collected with plastic loops. Then an endourethral swab (MW 142; Medical Wire and Equipment, Corsham, Wiltshire) was inserted 3-4 cm into the urethra, withdrawn, and agitated and expressed in a vial containing $1.8 \mathrm{ml}$ of 2SP (sucrose phosphate) medium containing $10 \%$ inactivated fetal calf serum but no antibiotics; this was frozen in liquid nitrogen. Tests for $C$ trachomatis were undertaken in McCoy cells treated with cycloheximide, which were stained with Giemsa, ${ }^{5}$ and Ureaplasma urealyticum and Mycoplasma hominis were sought by methods which have been described previously. ${ }^{6}$ Ureaplasma and $M$ hominis organisms were expressed as colour changing units (ccu). Blood was taken initially and 10 days later for full and differential leucocyte counts, erythrocyte sedimentation rates, liver function tests, measurement of urea and creatinine concentrations, and for syphilis serology tests, which were performed initially and repeated three months later.
Antimicrobial tests

Isolates of $C$ trachomatis and $U$ urealyticum obtained previously from unselected men with NGU were used to measure the respective minimum inhibitory concentrations (MICs) and minimum cidal concentrations (MCCs) of rosoxacin. In addition the MICs and MCCs of rosoxacin were estimated for strains of $C$ trachomatis isolated in the present study. The procedures for ureaplasmas were as described before, ${ }^{7}$ and those for $C$ trachomatis as presented below.

C trachomatis isolates were inoculated on to McCoy cell monolayers, which were centrifuged at $2800 \times g$ for one hour and incubated at $37^{\circ} \mathrm{C}$ for a further two hours, after which the medium was replaced with fresh medium containing only the antibiotic being tested. Three monolayers were used for each dilution of antibiotic. After 48 hours at $37^{\circ} \mathrm{C}$, two of the cell monolayers were stained and examined for the presence of inclusions. The MIC was taken as the highest dilution of antibiotic preventing the formation of inclusions. The third cell monolayer was disrupted, harvested, and then used to inoculate two fresh cell monolayer cultures. No antibiotic was added, and the monolayers were incubated at $37^{\circ} \mathrm{C}$ for 48 hours, after which they were stained and examined microscopically for inclusions. The MCC was taken as the highest dilution of antibiotic in the first cell passage which prevented the formation of inclusions in the subsequent passage.

\section{Results}

Of 84 men with NGU originally participating in the study, 62 returned for at least one follow up examination and had satisfactory urethral samples taken. They were well matched for age and previous history of sexually transmitted diseases. By chance, exactly half of the men had received rosoxacin and half had received triple tetracycline.

\section{CLINICAL RESPONSE TO TREATMENT}

Symptoms and signs of urethritis had resolved in only six (19\%) of 31 men treated with rosoxacin who were seen after 10 days, whereas urethritis had resolved in $18(58 \%)$ of 31 men who had been given triple tetracycline for 10 days $\left(x^{2}\right.$ test, $p=<0 \cdot 01$; $1 \mathrm{df}$, with Yates's correction). Six of the 18 men free of urethritis in the latter group then defaulted; the other 12 remained free of urethritis one to two weeks later. One of the six men free of urethritis in the group treated with rosoxacin defaulted, and two had recurrent urethritis.

Urethritis persisted in 38 men at day 10; 25 of them had received rosoxacin and 13 had received triple 
tetracycline. All were then treated with triple tetracycline (or further triple tetracycline). One to two weeks later 21 of these patients were cured, 10 had persistent urethritis, and seven had defaulted. Of this last group, four had been treated initially with rosoxacin and three with triple tetracycline.

\section{Adverse reactions}

Eight $(26 \%)$ of 31 patients treated with triple tetracycline reported side effects. These were mainly mild to moderate gastrointestinal complaints, although two patients complained of headaches and two of undue lethargy throughout treatment. Eleven $(31 \%)$ of 36 patients treated with rosoxacin reported side effects. One of these patients developed a severe idiosyncratic mucocutaneous reaction to rosoxacin after taking five capsules, and had to be withdrawn from the trial. He was given antihistamines, and the rash resolved slowly over three to four days. His urethritis had not been affected by the short course of rosoxacin but subsequently responded well to triple tetracycline. Four other patients who had received rosoxacin were also excluded from the main analysis because of incomplete assessments.

The remaining patients reporting side effects with rosoxacin complained of either mild gastrointestinal upset or symptoms of mild dysfunction of the central nervous system. In the latter group of patients, however, there was no obvious persistence of these symptoms with continued ingestion of the drug over 10 days. No appreciable change in haematological or biochemical variables was noted.

MICROBIOLOGICAL RESPONSE TO TREATMENT $C$ trachomatis organisms were isolated initially from $23(37 \%)$ of 62 men with NGU. They were reisolated at the first follow up visit from $12(92 \%)$ of 13 initially chlamydia positive patients who had received rosoxacin but from none of 10 initially chlamydia positive patients who had been given triple tetracycline. Furthermore, chlamydiae could not be reisolated from any patient one to two weeks after a 10 day course of triple tetracycline or from any patient who had been treated with triple tretracycline for seven days after the initial course of rosoxacin.

$U$ urealyticum organisms were isolated initially from $33(53 \%)$ of 62 men with NGU. They were reisolated at the first follow up visit from $12(80 \%)$ of 15 initially ureaplasma positive patients who had received rosoxacin but from only three $(17 \%)$ of 18 ureaplasma positive patients who had been given triple tetracycline. Of those given rosoxacin initially and then triple tetracycline (15 patients) or triple tetracycline initially (18 patients), large numbers of ureaplasmas $\left(10^{4}\right.$ to $\left.10^{6} \mathrm{ccu}\right)$ were reisolated from three. Two patients had had rosoxacin initially followed by triple tetracycline for seven days and one had had triple tetracycline for 17 days. In addition, 10000 times fewer ureaplasmas were reisolated from two patients who then defaulted. All the other patients became ureaplasma negative or defaulted.

$M$ hominis was isolated initially from $10(16 \%)$ of the 62 men with NGU, but always in association with $U$ urealyticum. Rosoxacin was given to five of these patients, and in addition to ureaplasmas the mycoplasma was reisolated from four $(80 \%)$ of them. Triple tetracycline was given subsequently to these four patients, and $M$ hominis was cleared from three of them. In one patient, however, a large number of mycoplasmas remained $\left(\geqslant 10^{6} \mathrm{ccu}\right)$ despite treatment with the tetracycline. None of five patients who were initially $M$ hominis positive and treated with triple tetracycline remained positive.

TABLE I Clinical response of patients with NGU to 10 days of treatment with rosoxacin or triple tetracycline in relation to the initial microbiological findings

\begin{tabular}{|c|c|c|c|c|c|c|c|c|c|c|}
\hline \multirow{3}{*}{$\begin{array}{l}\text { Clinical } \\
\text { response }\end{array}$} & \multicolumn{10}{|c|}{$\begin{array}{l}\text { No of men giving indicated clinical response to } \\
\text { rosoxacin }(R) \text { or triple tetracycline }(T T) \text { after initia } \\
\text { microbiological findings of: }\end{array}$} \\
\hline & \multicolumn{2}{|c|}{$C+U+$} & \multicolumn{2}{|c|}{$C+U-$} & \multicolumn{2}{|c|}{$C-U+$} & \multicolumn{2}{|c|}{$C-U-$} & \multicolumn{2}{|c|}{ Total } \\
\hline & $R$ & $T T$ & $R$ & $T T$ & $R$ & $T T$ & $R$ & $T T$ & $R$ & $T T$ \\
\hline $\begin{array}{l}\text { Complete } \\
\text { recovery } \\
\text { Partial }\end{array}$ & 0 & 3 & 0 & 3 & 2 & 7 & 4 & 5 & 6 & 18 \\
\hline $\begin{array}{l}\text { recovery } \\
\text { No recovery }\end{array}$ & $\begin{array}{l}0 \\
4\end{array}$ & $\begin{array}{l}1 \\
0\end{array}$ & $\begin{array}{l}2 \\
7\end{array}$ & $\begin{array}{l}1 \\
2\end{array}$ & $\begin{array}{l}4 \\
5\end{array}$ & $\begin{array}{l}5 \\
2\end{array}$ & $\frac{1}{2}$ & $\begin{array}{l}1 \\
1\end{array}$ & $\begin{array}{r}7 \\
18\end{array}$ & $\begin{array}{l}8 \\
5\end{array}$ \\
\hline Total & 4 & 4 & 9 & 6 & 11 & 14 & 7 & 7 & 31 & 31 \\
\hline
\end{tabular}

CORRELATION BETWEEN THE CLINICAL AND MICROBIOLOGICAL FINDINGS

Table I shows the clinical response to treatment in relation to the initial microbiological findings. The results for $M$ hominis are not included because of the small numbers and the complexity of the analysis. Overall, patients who initially harboured chlamydiae or ureaplasmas, or both micro-organisms, made a complete or partial clinical recovery less than half as often when given rosoxacin ( $8(33 \%)$ of 24 patients) as when given triple tetracycline $(20(83 \%)$ of 24 patients). Patients who did not harbour either of these micro-organisms initially responded clinically to rosoxacin and triple tetracycline in about the same proportions.

Table II shows that patients who failed to respond clinically when given rosoxacin were mainly, but not invariably, those in whom either chlamydiae or ureaplasmas persisted on the tenth day; those who 
TABLE II Relation between clinical and microbiological responses to treatment of patients with non-gonococcal urethritis

\begin{tabular}{llcc}
\hline & Clinical outcome at & \multicolumn{2}{l}{$\begin{array}{l}\text { No of patients with } \\
\text { micro-organisms* }\end{array}$} \\
\cline { 3 - 4 } Treatment & day 10 & Initially & At day 10 \\
\hline Rosoxacin & Complete recovery & 2 & 1 \\
& Partial recovery & 6 & 4 \\
Triple tetracycline & No recovery & 16 & 15 \\
& Complete recovery & 13 & 1 \\
& Partial recovery & 7 & 2 \\
& No recovery & 4 & 0 \\
\hline
\end{tabular}

*Chlamydiae or ureaplasmas, or both.

were given triple tetracycline were mainly free from micro-organisms after treatment, but not all recovered clinically. Further analysis of the ureaplasmal results is presented below.

FURTHER ANALYSIS OF THE FINDINGS FOR

U UREALYTICUM

$U$ urealyticum was isolated initially from more $(25$ $(64 \%)$ of 39 ) chlamydia negative men with NGU than chlamydia positive men (eight (35\%) of 23 ). Furthermore, as table III shows, more (geometric mean: $10^{5} \mathrm{ccu}$ ) ureaplasmas were recovered from chlamydia negative men than from chlamydia positive men (geometric mean: $10^{4} \mathrm{ccu}$ ).

Of 25 patients who were initially positive for ureaplasmas only, 11 were treated with rosoxacin. Ureaplasmas disappeared from three of them, one of whom became free of urethritis and the other two clinically improved. Thus ureaplasmas persisted in eight patients treated with rosoxacin, of whom seven $(83 \%)$ still had evidence of urethritis by day 10 . At this time, there were seven patients positive for ureaplasmas only who subsequently returned for follow up examinations. All these men made a complete clinical recovery when given a seven day course of triple tetracycline. Despite this, however,

TABLE III Relation between numbers of ureaplasmas isolated initially and chlamydial findings in men with nongonococcal urethritis

\begin{tabular}{lll}
\hline & $\begin{array}{l}\text { No of men from whom the indicated No } \\
\text { of ureaplasmas were isolated who were: }\end{array}$ \\
\cline { 2 - 3 } $\begin{array}{l}\text { No of } \\
\text { ureaplasmas }(\mathrm{ccu})\end{array}$ & $\begin{array}{l}\text { Chlamydia } \\
\text { positive }\end{array}$ & $\begin{array}{l}\text { Chlamydia } \\
\text { negative }\end{array}$ \\
\hline 0 & 15 & 14 \\
$10^{1}$ & 0 & 0 \\
$10^{2}$ & 0 & 1 \\
$10^{3}$ & 1 & 5 \\
$10^{4}$ & 4 & 7 \\
$10^{5}$ & 3 & 7 \\
$10^{6}$ & 0 & 5 \\
\hline
\end{tabular}

ureaplasmas were recovered from three men $\left(10^{4}\right.$ to $10^{6} \mathrm{ccu}$ ) on day 17. It appeared, therefore, that these particular strains resistant to tetracycline were not a cause of persistent NGU.

\section{SENSITIVITY OF MICRO-ORGANISMS TO ANTIBIOTICS IN VITRO \\ $C$ trachomatis}

Seven strains of $C$ trachomatis from unselected patients with NGU and the 12 strains recovered from patients after treatment with rosoxacin in this study were tested for their sensitivity to rosoxacin and a tetracycline (minocycline). The MICs of rosoxacin ranged from 10 to $80 \mathrm{mg} / \mathrm{l}$ and the MCCs ranged from 20 to $80 \mathrm{mg} / \mathrm{l}$. This compares with an MIC of minocycline of $<0.001 \mathrm{mg} / \mathrm{l}$ and an MCC of $<0.001 \mathrm{mg} / \mathrm{l}$. In a previous study in this laboratory the MIC of triple tetracycline was found to be $<0.005 \mathrm{mg} / \mathrm{l}$ (Evans RT, unpublished observation).

\section{$U$ urealyticum}

The MICs of rosoxacin for the first eight serotypes of $U$ urealyticum and for eight freshly isolated strains ranged from 0.5 to $>62 \mathrm{mg} / \mathrm{l}$. The MCCs ranged from 4 to $\geqslant 62 \mathrm{mg} / \mathrm{l}$.

\section{Discussion}

It is apparent that rosoxacin is ineffective in the treatment of NGU. Only a few patients recovered clinically. Furthermore chlamydiae or ureaplasmas, or both micro-organisms, were reisolated from nearly all patients who failed to respond clinically, and the relative inactivity of rosoxacin in in vitro tests was consistent with the clinical observations. Rosoxacin inhibited some ureaplasma strains in vitro but, at best, was at least 500 times less active than the tetracyclines tested previously. ${ }^{78}$ Our clinical and microbiological observations on the ineffectiveness of rosoxacin are clearly at variance with the reports of French workers, ${ }^{34}$ and we are unable to understand their claims. We think that our results underline the value of the properly controlled clinical trial in assessing the effectiveness of any antibiotic.

When it became apparent that an unusually large proportion of patients were failing to respond clinically to treatment, the code was broken, the results assessed, and the trial was curtailed. The ineffectiveness of rosoxacin meant that, in essence, we were inadvertently conducting a "placebo" controlled trial of a tetracycline. This has allowed us to look again at some aspects of the aetiology of $\mathrm{NGU}$, although the number of patients investigated was necessarily kept small and the information is therefore limited. Nevertheless, as we have noted before, ${ }^{9}$ treatment with tetracycline was more 
effective than the "placebo" (that is, rosoxacin) in patients who initially yielded both chlamydiae and ureaplasmas, in those with chlamydiae only, and also in those who harboured ureaplasmas only. If the ureaplasmas behaved only as passengers, NGU that was ureaplasma positive only would not be expected to respond better to tetracycline than to rosoxacin unless another undiscovered micro-organism, which was also sensitive to tetracyclines, was responsible for the disease. This possibility cannot yet be excluded, ${ }^{1011}$ but would have to be considered equally in patients infected by chlamydiae. As the latter micro-organisms are an accepted cause of NGU, the similar response to treatment of chlamydia positive and ureaplasma positive patients suggests by inference, at least until there is unequivocal evidence to the contrary, that ureaplasmas also have an aetiological role. In addition, we noted that ureaplasmas were associated more with chlamydia negative NGU than with chlamydia positive NGU, not only qualitatively but also quantitatively. A similar finding has been put forward by Bowie et al linking ureaplasmas with this form of disease in particular, ${ }^{12}$ but it is one that we have not observed before even with a large number of patients. ${ }^{13}$ The reason for this is not clear. Three (9\%) of 34 ureaplasma strains were resistant to tetracycline, an incidence in keeping with that recorded by us previously. ${ }^{8}$ Despite some evidence for the pathogenicity of ureaplasmas, it is of interest that these strains resistant to tetracycline appeared not to be associated with persistent urethritis in the way described by other workers. ${ }^{14}$ The possibility that there was a mixture of strains resistant and those sensitive to tetracycline, however, of which only the latter were associated with NGU, needs to be investigated.

Finally, it is of interest that the "placebo" was about as effective clinically as tetracycline in the group of patients from whom neither chlamydiae nor ureaplasmas were isolated (C- U-, table I). This finding could be explained either on the basis that these patients had self limiting disease that only appeared to be affected by treatment, or that rosoxacin was not behaving as a placebo in this group, but was inhibiting a micro-organism that was as sensitive to this antibiotic as to tetracycline. This emphasises the point that certain aspects of the aetiology of NGU remain unresolved.

We thank the staff of the Praed Street Clinic, particularly Mr Alec Whitehead and Mr Tony Kendall of St Mary's Hospital pharmacy, for their help. We thank Sterling Winthrop for supplying the rosoxacin, and Dr Colman Cleary for all his help.

\section{References}

1. Handsfield $\mathbf{H}$, Judson $\mathrm{F}$, Holmes KK. Treatment of uncomplicated gonorrhea with rosoxacin. Antimicrob Agents Chemother 1981; 20:625-9.

2. Walsh RJ, Scott R, Bittiner JB, Shahidullah M, Slack RCB. Acrosoxacin in the treatment of uncomplicated gonorrhoea. British Journal of Venereal Diseases 1983;59:242-4.

3. Siboulet A, Bohbot JM, Catalan F, Siboulet A, Henry-Suchet J. Les infection uretro-genitales a Chlamydia trachomatis. Bulletins et Memoire de la Societe de Medecin de Paris 1982; 10: 103-13.

4. Siboulet A, Bohbot JM, Catalan F, Siboulet A, Henry-Suchet J. Chlamydia trachomatis genito-urethral infections. Proceedings of the 13th International Congress of Chemotherapy, 1983; symposium 51-4, 15-22.

5. Thomas BJ, Evans RT, Hutchinson GR, Taylor-Robinson D. Early detection of chlamydial inclusions combining the use of cycloheximide-treated McCoy cells and immunofluorescence staining. J Clin Microbiol 1977;6:285-92.

6. Taylor-Robinson D, Furr PM. Recovery and identification of human genital tract mycoplasmas. Isr J Med Sci 1981; 17:648-53.

7. Taylor-Robinson D, Furr PM. The static effect of rosaramicin on Ureaplasma urealyticum and the development of antibiotic resistance. J Antimicrob Chemother 1982; 10: 185-91.

8. Evans RT, Taylor-Robinson D. The incidence of tetracyclineresistant strains of Ureaplasma urealyticum. J Antimicrob Chemother 1978; 4:57-63.

9. Prentice MJ, Taylor-Robinson D, Csonka GW. Non-specific urethritis. A placebo-controlled trial of minocycline in conjunction with laboratory investigations. British Journal of Venereal Diseases 1976;52:269-75.

10. Taylor-Robinson $D$. Mycoplasma infections of the human urogenital tract with particular reference to non-gonococcal urethritis. Ann Microbiol (Paris) 1984; 135A: 129-34.

11. Fontaine EA, Taylor-Robinson D, Hanna NF, Coufalik ED. Anaerobes in men with urethritis. British Journal of Venereal Diseases 1982; 58:321-6.

12. Bowie WR, Wang S-P, Alexander ER, et al. Etiology of nongonococcal urethritis. Evidence for Chlamydia trachomatis and Ureaplasma urealyticum. J Clin Invest 1977;59:735-42.

13. Taylor-Robinson D, Evans RT, Coufalik ED, et al. Ureaplasma urealyticum and Mycoplasma hominis in chlamydial and non-chlamydial nongonococcal urethritis. British Journal of Venereal Diseases 1979;55:30-5.

14. Stimson JB, Hale J, Bowie WR, Holmes KK. Tetracyclineresistant Ureaplasma urealyticum: a cause of persistent nongonococcal urethritis. Ann Intern Med 1981;94:192-4. 